\section{UAB}

Universitat Autònoma de Barcelona

\section{Dipòsit digital \\ D/D de la UAB}

This is the accepted version of the article:

Bertero, Enrico; Hasegawa, Madoka; Staubli, Samuel; [et al.]. «Electrodeposition of amorphous Fe-Cr-Ni stainless steel alloy with high corrosion resistance, low cytotoxicity and soft magnetic properties». Surface \& coatings technology, Vol. 349 (Sep. 2018), p. 745-751. DOI 10.1016/j.surfcoat.2018.06.003

This version is avaible at https://ddd.uab.cat/record/203893

under the terms of the (c))Br-NC-ND license 


\title{
Electrodeposition of amorphous Fe-Cr-Ni stainless steel alloy with highccorrosion resistance, low cytotoxicity and soft magnetic properties
}

\author{
Enrico Bertero a,b,w, Madoka Hasegawa $a^{a, 1,2}$, Samuel Staublic, Eva Pellicerd, \\ Inge K. Herrmann', Jordi Sortd,e, Johann Michlera, Laetitia Philippea \\ a Empa - Swiss Federal Laboratories for Materials Science and Technology, Laboratory for \\ Mechanics of Materials and Nanostructures, Feuerwerkerstrasse 39, 3602 Thun, \\ Switzerland \\ b Ecole Polytechnique Fédérale de Lausanne, Tribology and Interfacial Chemistry Group, \\ Materials Institute Station 12 (SCI-STI-SM), 1015 Lausanne, Switzerland \\ c Empa - Swiss Federal Laboratories for Materials Science and Technology, Department \\ Materials Meet Life, Lerchenfeldstrasse 5, 9014 St. Gallen, Switzerland \\ d Physics Department, Sciences Faculty, Building C3, Autonomous University of Barcelona \\ (UAB), 08193 Bellaterra, Spain \\ e Institució Catalana de Recerca i Estudis Avançats (ICREA), Pg. Lluís Companys 23, 08010 \\ Barcelona, Spain
}

Keywords: Electrodeposition, Stainless steel, Corrosion resistance, Cytotoxicity, Soft ferromagnetic material

\begin{abstract}
A B S T R A C T
Electrodeposition of $\mathrm{Fe}-\mathrm{Cr}$-Ni alloy thin films with high corrosion resistance, low cytotoxicity and soft-magnetic properties is reported. Fe-Cr-Ni films with $\mathrm{Cr}$ contents from $5 \mathrm{wt} \%$ to $40 \mathrm{wt} \%$ were prepared by adjusting the current density during electrodeposition and the film properties were investigated. An excellent corrosion resistance was found in films with high $\mathrm{Cr}$ contents ( $\geq 30 \mathrm{wt} \%$ ), where anodic polarization performance similar to those of AISI 304 and 316L stainless steels was observed in both acidic and biological media. Cell compatibility, measured by lactate dehydrogenase assay, demonstrated that electrodeposited Fe-Cr-Ni films exhibit low cytotoxicity, comparable to AISI 304 and 316L stainless steels. Unlike AISI 304 and AISI 316L, which are conventional austenite stainless steels, the electrodeposited Fe-Cr-Ni films were found to be amorphous. This leads to soft ferromagnetic characteristics, which are dependent on the alloy composition. The unique combination of excellent corrosion resistance, low cytotoxicity and tunable magnetic properties makes this material interesting for functional coatings and components in advanced biological and medical microsystems.
\end{abstract}

\section{Introduction}

Electrodeposition is an appealing technique to synthesize thin films of metals and alloys because of its cost effectiveness, scalability and versatility. This is why it is widely used to fabricate functional coatings for various industrial applications. In addition, this technique can be combined with ultra-violet (UV) or X-ray lithography, e.g. LIGA [a German acronym for Lithographie, Galvanoformung, Abformung (Lithography, Electroplating, and Molding)], processes [1,2] to create precisely designed free-standing microcomponents. Electrodeposition is nowadays employed to grow materials into many different templates with micro- and nano-meter-scale features: substrates containing threedimensional structures patterned by two photon lithography [3], 
anodic porous alumina or polycarbonate membranes [4, 5], or self-assembled colloidal crystals [6-10]. These techniques pave the way to the design of a large variety of nano and micro-scale advanced materials in a relatively simple manner.

From scientific and engineering perspectives, electrodeposition of stainless steel is of great technological interest. Stainless steel, which is a Fe-alloy with at least $10.5 \mathrm{wt} \%$ of $\mathrm{Cr}$, is one of the most widely used materials in metallurgy because of its excellent corrosion resistance and outstanding mechanical properties. Among many different grades of stainless steels, AISI 300-series austenitic stainless steels are particularly important, because they show superior corrosion resistance with respect to other stainless steels. Moreover, some of them can be employed for biological and medical applications thanks to their sufficient biocompatibility.

Recent growing demands for miniaturization in high-tech industries have pushed the development of several microfabrication techniques for stainless steel, such as additive manufacturing (3D printing) using metal powder [11] and micro-powder injection molding [12]. However, these micromachining technologies still require improvement with regard to cost, performance, process time and precision, which are severe technological challenges, mostly due to the high chemical resistance and hardness of stainless steel. In addition, it is not straightforward to grow steel in thin film form. In this context, the electrodeposition and concurrent patterning of stainless steel is a promising microfabrication technique which is likely to revolutionize stainless steel technology.

Electrodeposition of stainless steel and $\mathrm{Fe}-\mathrm{Cr}$ based alloys from $\mathrm{Cr}$ (III)-containing solutions has been studied for many years. The main efforts were directed towards studying the influence of electrolyte and deposition parameters on the targeted elemental composition of the films $[13,14]$ and on investigating the mechanisms behind such complex electrochemical systems [15]. As a result, relatively thick (tens of micrometers) coatings with uniform compositions have been produced. So far, however, significantly thick and crack-free self-standing electrodeposits were only achieved for $\mathrm{Fe}-\mathrm{Ni}$-Cr alloys with relatively high $\mathrm{Ni}$ and low $\mathrm{Cr}$ contents which do not match the corrosion resistance of bulk stainless steel [16]. The quality (morphology, adherence and porosity) of the electrodeposited coatings is critical for technological applications such as corrosion protective coatings and LIGA additive manufacturing. Therefore, there is clearly a need for further improvement in this field. In particular, electrodeposited Fe-Cr-Ni has great potential for the fabrication of Micro-Electromechanical Systems (MEMS) for a variety of applications, including bio-medical implants. For such applications, low cytotoxicity, excellent corrosion resistance, good mechanical features and soft magnetism are essential properties. We previously demonstrated that an Fe-Cr-Ni alloy plating bath based on chloride salts and containing glycine as a complexing agent yields amorphous or nanocrystalline Fe-Cr-Ni alloy films with much a 
higher Cr content and mechanical properties comparable to or even higher than AISI 304 [17]. Here, we electrodeposit micrometers-thick crack-free $\mathrm{Fe}-\mathrm{Cr}-\mathrm{Ni}$ films with high $\mathrm{Cr}$ content and assess their corrosion performance, cytotoxicity and magnetic properties, taking austenitic bulk stainless steels as reference materials.

\section{Material and methods}

\subsection{Electrodeposition of Fe-Cr-Ni}

The electrodeposition of Fe-Cr-Ni was performed in a glass beaker equipped with a water jacket for temperature control. The temperature of the electroplating bath was set to $22{ }^{\circ} \mathrm{C} \pm 0.5^{\circ} \mathrm{C}$ using a temperature controlled circulator (Julabo, F12-ED). The electrodeposition of Fe-Cr$\mathrm{Ni}$ was performed onto a silicon substrate covered with a sputter-coated $\mathrm{Au}$ layer $(100 \mathrm{~nm})$ deposited on top of a $\mathrm{Cr}$ adhesion layer (5 nm). Prior to each electrodeposition experiment, the substrate was cleaned in freshly prepared Piranha solution $\left(30 \% \mathrm{H}_{2} \mathrm{O} 2: \mathrm{H}_{2} \mathrm{SO}_{4}=1: 3\right)$ and thoroughly rinsed in deionized water $(18.2 \mathrm{M} \Omega \cdot \mathrm{cm})$. Subsequently, the substrate was partially masked with plastic tape in order to expose a plating area of $1.5 \mathrm{~cm} \times 1.5 \mathrm{~cm}$. A Pt mesh ( $80 \mathrm{mesh}, 25 \mathrm{~mm} \times 35 \mathrm{~mm}$, ALS Co., Ltd) was used as a counter-electrode. The bath composition is shown in Table 1. All of the chemicals were reagent grade (Sigma-Aldrich) and were used as-received without any further purification. The bath constituents were mixed by following the procedure described in Ref [17]. Electrodeposition was carried out at a current density ranging from -50 to $-100 \mathrm{~mA} / \mathrm{cm} 2$ using a potentiostat (PGSTAT 30, Metrohm Autolab B.V.) controlled by the NOVA (version 1.7) software. The surface morphology of the Fe-Cr-Ni samples was observed by field-emission scanning electron microscopy (FE-SEM, Hitachi S-4800, Hitachi High-Technologies Corporation). Crystal structures were characterized by grazing-incidence X-ray diffraction (GI-XRD, Brucker) with a $\mathrm{Cu}$ Ka radiation source $(40 \mathrm{kV}, 40 \mathrm{~mA})$. The incident angle was fixed to $10^{\circ}$. The diffraction patterns were recorded in the $2 \theta$ range between $30^{\circ}$ and $100^{\circ}$.

The elemental compositions ( $\mathrm{Fe}, \mathrm{Cr}$ and $\mathrm{Ni}$ contents) of the specimens and the thicknesses of the films were estimated by X-ray fluorescence (XRF, Fischerscope ${ }^{\circledR}$ X-RAY XDV ${ }^{\circledR}$-SDD, Fischer Technology).

The measurements were performed at 25 uniformly distributed points on each sample. The alloy composition map of an electrodeposited sample obtained from these measurements shows that the Cr content is higher at the edges of the sample than the center (Cr variation $\approx 15 \mathrm{wt}$ $\%$ ) due to an uneven current distribution during electrodeposition. Therefore, in this paper, the mean of 25 measurements was chosen as the representative concentration of the sample. Glow discharge optical emission spectroscopy (GDOES, JY 5000 RF, HORIBA Jobin Yvon) was performed to assess the presence of impurities. The measurements show that the electrodeposited films contain approximately $4 \mathrm{wt} \%$ carbon, 
$2 \mathrm{wt} \%$ nitrogen and traces of oxygen. There was no clear correlation between the compositions of the alloys and the concentrations of impurities.

\subsection{Anodic linear sweep voltammetry (LSV)}

The corrosion behavior of the Fe-Cr-Ni electrodeposits was analyzed by anodic linear sweep voltammetry in a $0.5 \mathrm{M} \mathrm{H} 2 \mathrm{SO} 4$ aqueous solution at $23^{\circ} \mathrm{C}$ and in a DMEM (Dulbecco's Modified Eagle Medium) biological medium at neutral $\mathrm{pH}$ at $37^{\circ} \mathrm{C}$. In addition to the electrodeposited films, disks of AISI 316L (Cr18/Ni10/Mo3) and AISI 304 (Cr18/Ni10) were analyzed as reference samples. The measurements were performed in a conventional three electrode electrochemical cell. The test solution was freshly prepared and de-aerated in the electrochemical cell by Ar bubbling for at least 30 min prior to each experiment. A Fe-Cr-Ni electrodeposited film was then placed in a Teflon sample holder with a circular exposed electrode area, $9 \mathrm{~mm}$ in diameter. Pt wire was used as a counter-electrode, while a $\mathrm{Ag} / \mathrm{AgCl}$ electrode was used as a reference electrode. For AISI 316L and AISI 304 disks, samples were cleaned in acetone with sonication for $15 \mathrm{~min}$, followed by rinsing in ethanol. Then, they were further cleaned in Piranha solution for a few minutes to remove any residual surface contamination. Finally, the electrodeposited films were cleaned in deionized water prior to each measurement. The cleaned samples (AISI 304, AISI 316L and electrodeposited samples) were immersed in the test solution $(0.5 \mathrm{M} \mathrm{H} 2 \mathrm{SO} 4)$ for 15 min prior to each measurement. For the acidic solution, a cathodic pre-treatment was carried out at $-0.6 \mathrm{~V}$ vs. $\mathrm{Ag} / \mathrm{AgCl}$ for $15 \mathrm{~min}$. The anodic linear sweep voltammetry was performed from $-0.6 \mathrm{~V}$ to $+1.5 \mathrm{~V}$ vs. $\mathrm{Ag} / \mathrm{AgCl}$ at a scan rate of $1 \mathrm{mV} / \mathrm{s}$ immediately after the cathodic pre-treatment. For the DMEM biological solution, no cathodic pre-treatment was employed, and the anodic LSV was performed under the same conditions as for the acidic medium.

\subsection{Cytotoxicity tests}

The samples were sterilized by incubating them overnight in $70 \%$ ethanol/water. Afterwards, they were thoroughly washed with phosphatebuffered saline (PBS) and transferred to a 6-well cell culture plate. Cells (A549, human adenocarcinoma cell line) were seeded into 6 -well cell culture plates containing the steel samples $(n=3$ for every plate). Cells were seeded on the samples at a density of 100,000 per $\mathrm{mL}$ in DMEM medium containing 1\% fetal bovine serum (FBS) and antibiotics. For the positive control, cells were lysed with $0.1 \%$ Triton $\mathrm{X}$ (total lysis). Cells not exposed to samples served as negative control. After $24 \mathrm{~h}$, supernatants were collected and lactate dehydrogenase release into the medium was measured by the lactate dehydrogenase (LDH) kit following the manufacturer's protocol (NonRadioactive Cytotoxicity Assay, Promega). The results are expressed relative to the positive control (total lysis, equivalent to $100 \%$ cell death). Cells were 
then fixed with $4 \%$ paraformaldehyde (PFA) for $12 \mathrm{~h}$ at $4{ }^{\circ} \mathrm{C}$ and permeabilized with $0.1 \%$ Triton $\mathrm{X}$ for $2 \mathrm{~min}$. The cytoskeleton of the cells was then stained with Phalloidin Alexa 488 (Life Technologies, following the manufacturer's protocol). The nucleus was stained with DAPI ( $4^{\prime}$, 6-diamidino-2-phenylindole). Cells were then imaged using a Zeiss Axio Fluroescence microscope. For scanning electron microscopy, cells were gradually dehydrated with ethanol $(30 \%, 50 \%, 70 \%, 80 \%$, $90 \%, 100 \%(3 \times)$ for 5 min each), coated with $7 \mathrm{~nm}$ of gold and imaged in a FE-SEM (Hitachi S-4800, Hitachi High-Technologies Corporation) using an accelerating voltage of $2 \mathrm{kV}$.

\subsection{Magnetic characterization}

Hysteresis loops were recorded at room temperature in a vibrating sample magnetometer (VSM) from Oxford Instruments, using a maximum applied magnetic field of 1 Tesla. The magnetic field was applied along the film plane direction.

\section{Results and discussion}

\subsection{Electrodeposition of Fe-Cr-Ni films}

Generally, in stainless steel alloys, the Cr content is the prime factor determining the corrosion resistance. In order to understand and optimize the effect of composition on the resulting properties, $\mathrm{Fe}-\mathrm{Cr}-\mathrm{Ni}$ films with various $\mathrm{Cr}$ contents were prepared. Fe-Ni deposition, which follows the so-called anomalous co-deposition [15], leads to less-noble Fe depositing preferentially with respect to $\mathrm{Ni}$, even if the Ni:Fe ratio inside the bath is much greater than one (Table 1). However, during codeposition of $\mathrm{Fe}-\mathrm{Cr}-\mathrm{Ni}$ in this plating system, cathodic reactions of $\mathrm{Fe}$ and $\mathrm{Ni}$ ions are limited by mass-transfer. On the other hand, $\mathrm{Cr}$, whose deposition potential is more negative than those of $\mathrm{Fe}$ and $\mathrm{Ni}$, is deposited in the charge-transfer limited or mixed regime. Hence, the deposition rate of $\mathrm{Cr}$ is highly dependent on the polarization of the electrode (or the applied current density), while those of Fe and Ni should not be affected by the current density, as long as the mass-transfer state is unchanged. Thus, the $\mathrm{Cr}$ content in a deposit can be adjusted by simply tuning the current density. Therefore, in this study, a series of electrodepositions is carried out at various current densities in order to obtain Fe-Cr-Ni deposits with different Cr contents.

Fig. 1a shows the dependence of composition on the current density. As expected, the Cr content increases from $5 \mathrm{wt} \%$ to $38 \mathrm{wt} \%$ with an increase in the cathode current density from $-50 \mathrm{~mA} / \mathrm{cm} 2$ to $-100 \mathrm{~mA} / \mathrm{cm} 2$. This consequently leads to a decrease of $\mathrm{Fe}$ and $\mathrm{Ni}$ contents from $78 \mathrm{wt} \%$ to $48 \mathrm{wt} \%$ and from $20 \mathrm{wt} \%$ to $13 \mathrm{wt} \%$, respectively. It should be noted that the ratio of Fe:Ni essentially did not change $(\sim 4)$, which agrees with the deposition mechanism described above. 
Avoiding or minimizing cracking in electrodeposited films is a challenge for $\mathrm{Cr}$ and its alloys, and this limits the maximum achievable thickness of the coatings. As proposed by Snavely [18], cracking is related to the incorporation of chromium hydrides ( $\mathrm{CrH}$ and/or $\mathrm{CrH} 2$ ), which subsequently decompose into metallic $\mathrm{Cr}$ and hydrogen atoms, thus resulting in shrinkage of the films. Here, cracks were observed in Fe-Cr-Ni electrodeposits when the films exceeded a certain thickness. Typically, cracks appear on the film's surface after some hours or days of storage once the samples are prepared. This observation suggests structural changes in the deposits after electrodeposition, which supports the aforementioned mechanism.

SEM observations of Fe-Cr-Ni electrodeposits with various compositions revealed that the films are free of cracks for thicknesses up to $5 \mu \mathrm{m}$, regardless of the alloy composition. Therefore, in this study, we prepared films with thickness of around $5 \mu \mathrm{m}$ for the characterization of their corrosion resistance and cytotoxicity. Fig. 1b shows top-view SEM images of 5-micrometer-thick Fe-Cr-Ni films with different $\mathrm{Cr}$ contents. The Fe-Cr-Ni films are in general very smooth (roughness $\leq 200 \mathrm{~nm}$ ), although a few nodule-like deposits were occasionally observed on the surface. The size of these nodules varies from sub-micrometer to a few micrometers and the number of nodules also varied among samples. While no clear relationship was observed between the nodule formation and the alloy composition, the number of nodules tends to increase with an increase of thickness, implying that nodules nucleate randomly but remain during film growth.

The crystallographic structures of the Fe-Cr-Ni electrodeposits with different compositions were analyzed by GI-XRD (Fig. 2). We previously reported [17] that Fe-Cr-Ni deposits containing 25-30 wt\% $\mathrm{Cr}$ are amorphous, unlike the austenitic stainless steels AISI 304 and AISI 316L. In agreement with the previous result, no visible peaks were observed in any of the GI-XRD profiles of the Fe-Cr-Ni electrodeposits in the range of $\mathrm{Cr}$ content between $5 \mathrm{wt} \%$ and $51 \mathrm{wt} \%$. These results reveal that the microstructure of the Fe-Cr-Ni deposits is not significantly affected by the composition, at least in the range of $\mathrm{Cr}$ content investigated in this study.

\subsection{Anodic linear sweep voltammetry}

The excellent corrosion resistance of stainless steels is associated with the native surface oxide which passivates the surface and protects the alloy from anodic dissolution [19-21]. Extensive studies of the passivation film have shown that its composition $[22,23]$, thickness [24] and microstructure $[25,26]$ significantly affect the corrosion resistance. Therefore, the investigation of surface oxides, especially their formation and anodic dissolution, provides important insights into corrosion of stainless steels.

In this study, the anodic linear sweep voltammograms of the samples 
were measured in $0.5 \mathrm{M}$ aqueous sulfuric acid. We employed a cathodic pre-treatment (or activation), which is a commonly used surface preparation method for anodic polarization studies of stainless steels [24, 27-29], in order to remove the native oxide layer, thereby enabling the characterization of oxide formation and its anodic dissolution during a potential sweep. The cathodic pretreatment was performed at $-0.6 \mathrm{~V}$ vs. $\mathrm{Ag} / \mathrm{AgCl}$ for $15 \mathrm{~min}$ in the test solution in order to remove the native oxide layer. The polarization measurement was performed immediately after the pre-treatment. The polarization curves obtained with this procedure are reasonably reproducible. Fig. 3a compares the anodic polarization curves of an electrodeposited $\mathrm{Fe}-\mathrm{Cr}$ Ni film (32 wt\% Cr), AISI 304 and AISI 316L. Table 2 lists the extracted corrosion parameters. All polarization curves show the typical activepassive-transpassive transition. The anodic peak for the passive oxide formation appears around $-0.25 \mathrm{~V}$ and the passivation plateau continues until the breakdown potential around $+1.0 \mathrm{~V}$, where the transpassive formation of soluble $\mathrm{Cr} 2 \mathrm{O} 7$

- begins [24]. The anodic polarization

curve of an electrodeposited sample ( $32 \mathrm{wt} \% \mathrm{Cr}$ ) in the passive region overlaps closely with those of AISI 316L and AISI 304, demonstrating that the electrodeposited sample exhibits a passivation behavior similar to those of standard austenitic stainless steels. On the other hand, some characteristic differences between the electrodeposited sample and standard stainless steels are observed. Primarily, the cathodic reaction (hydrogen evolution) on the electrodeposited sample is significantly enhanced with respect to AISI 316L and AISI 304 , and this consequently results in the positive shift of the zero-current potential. Secondly, the transpassive breakdown starts at a slightly more positive potential on the electrodeposited sample than in standard stainless steel samples. The difference in electrochemical behavior between the electrodeposited sample and standard stainless steels is attributed to the dissimilarities in microstructure and chemical composition of the passive oxide film. As shown previously, electrodeposited $\mathrm{Fe}-\mathrm{Cr}-\mathrm{Ni}$ is amorphous, in contrast to its metallurgical crystalline counterpart [17]. Moreover, the incorporation of hydroxides and hydrides in the coating from enhanced hydrogen evolution reactions [30, 31] results in a passive oxide layer which differs in chemical composition from those of the AISI stainless steels. Fig. $3 \mathrm{~b}$ shows the polarization curves for electrodeposited samples containing various contents of $\mathrm{Cr}$. The graph reveals that the $\mathrm{Cr}$ content significantly affects the passivation performance of electrodeposited Fe-Cr-Ni. The polarization curves of samples with 12 and $18 \mathrm{wt} \%$ Cr show two broad current peaks in the potential ranges between $-0.2 \mathrm{~V}$ and $+0.4 \mathrm{~V}$ and between $+0.4 \mathrm{~V}$ and $+1.0 \mathrm{~V}$. These peaks are attributed to the formation of soluble $\mathrm{Fe} 2+$ and $\mathrm{Fe} 3+[24]$, respectively. It is widely accepted that the corrosion protection is brought about by the formation of a chromic 
oxide matrix which stabilizes these Fe species. As can be seen in the graph, the current peaks in the passive region become smaller with an increase in the $\mathrm{Cr}$ content up to around $30 \mathrm{wt} \%$. The best results are obtained around this $\mathrm{Cr}$ content, and for the best cases (i.e. $32 \mathrm{wt} \% \mathrm{Cr}$, $37 \mathrm{wt} \% \mathrm{Cr}$ ), the polarization curves in the passive region are very close to those of AISI 304 and AISI 316L, confirming the outstanding corrosion resistance of these coatings. Further increase in the Cr content does not provide any significant changes in corrosion passivation, which is in agreement with the known effects of $\mathrm{Cr}$ on corrosion properties of stainless steels [24, 28].

Additionally, anodic linear sweep voltammetry tests of the samples were performed in a biological medium, namely Dulbecco's Modified Eagle Medium (DMEM) using the same polarization parameters as for the acidic case, but without implementing a cathodic pre-treatment, thus maintaining the native oxide layer intact. These measurements allowed for assessing the corrosion behavior of electrodeposited Fe-Cr$\mathrm{Ni}$ films in a physiological solution, which resembles a potential biomedical application environment. Fig. 3c compares the anodic polarization curves of an electrodeposited Fe-Cr-Ni film (34 wt\% Cr), AISI 304 and AISI 316L. The extracted corrosion parameters for those samples (Table 2) are in agreement with results previously obtained for standard stainless steels in other physiological media [32]. Electrodeposited Fe-Cr-Ni presents a smaller catalytic effect on the cathodic reaction than standard stainless steels, which could explain its higher passive current in the anodic region. The absence of current spikes in the passive domain, together with visual inspection of the samples after tests, confirmed that pitting was not initiated. Moreover, the transpassive domain (starting around $0.7 \mathrm{~V}$ vs. $\mathrm{Ag} / \mathrm{AgCl}$ ) is consistent with $\mathrm{Cr}$ (III) to $\mathrm{Cr}(\mathrm{VI})$ dissolution and water oxidation at neutral $\mathrm{pH}$. In this region, the variation of current values at the plateaus can be explained by the differences of $\mathrm{Cr}$ dissolution among the samples: electrodeposited Fe-Cr-Ni is much richer in $\mathrm{Cr}$ than standard austenitic stainless steels.

Overall, in the case of an acidic solution, polarization measurements of the electrodeposited samples clearly show the formation of a highly passive surface oxide film, similar to those of the standard stainless steels. Moreover, polarization scans in a biological medium (DMEM) confirm that electrodeposited $\mathrm{Fe}-\mathrm{Cr}-\mathrm{Ni}$ also presents good corrosion properties in a physiological cell-culture environment, with no signs of pitting.

\subsection{Cytotoxicity tests}

With regard to the potential biomedical applications of electrodeposited Fe-Cr-Ni, cell adhesion and compatibility issues are critical. We therefore compared cell adhesion and morphology on electrodeposited Fe-Cr-Ni samples to those of commonly used stainless steels (AISI 304 and AISI 316L). Fig. 4a-c reveals comparable cell adhesion 
for all three samples investigated, with no visible cell morphological differences among them. SEM micrographs (Fig. 4d,e) further show comparable morphology and cell surface adhesion between AISI 316L stainless steel (Fig. 4e) and electrodeposited Fe-Cr-Ni (Fig. 4d) samples. Cell compatibility was confirmed by quantifying lactate dehydrogenase (LDH) release into the medium (Fig. 4f). LDH is released in response to membrane damage and is a sensitive marker for cytotoxicity. Again, there is no difference between the various samples and cell death is comparable to the negative control (no steel, cells only sample).

\subsection{Magnetic characterization}

Contrary to the non-magnetic character of conventional (i.e. crystalline) austenitic steels, the electrodeposited amorphous-like Fe-Cr-Ni films are ferromagnetic. Representative hysteresis loops of the various investigated coatings, measured along the in-plane direction, are shown in Fig. 5a. All films exhibit a soft ferromagnetic behavior, with coercivity values in the range 5-40 0e and saturation magnetization, Ms, which decreases linearly with respect to the $\mathrm{Cr}$ wt\% (see Fig. 5b). For a Cr content exceeding $40 \mathrm{wt} \%$, the electrodeposited alloys become fully non-magnetic. These results are in agreement with previous studies on Fe-Cr based metallic glasses [33, 34], where the dilution of Fe with $\mathrm{Cr}$ was reported to lead to a linear decrease of the overall magnetization due to a decrease of the Fe-Fe exchange interactions [34], which was also manifested by a reduction of the Curie temperature. Additionally, the exchange interactions between $\mathrm{Fe}$ and $\mathrm{Cr}$ atoms are known to be antiferromagnetic [33], thus further contributing to the decrease of Ms. Overall, our results reveal that by varying the current density during electrodeposition the magnetic response of Fe-Cr-Ni alloys can be highly tailored, as occurs in other electrodeposited systems such as $\mathrm{Cu}$ $\mathrm{Ni}$ [35]. This is an interesting result for the potential implementation of this type of coating in magnetically-actuated micro/nano-electro-mechanical systems (MEMS/NEMS).

\section{Conclusions}

Amorphous $\mathrm{Fe}-\mathrm{Cr}-\mathrm{Ni}$ thin films with various $\mathrm{Cr}$ contents were prepared by electrodeposition.

1. The anodic linear sweep voltammetry demonstrated that:

- In aqueous sulfuric acid solution, electrodeposited Fe-Cr-Ni films

with a $\mathrm{Cr}$ content of $30 \mathrm{wt} \%$ or more exhibit an excellent passivation behavior, which is similar to that of AISI 304 and AISI 316L austenitic stainless steels.

- The electrodeposited film with $32 \mathrm{wt} \% \mathrm{Cr}$ in such acidic media shows passivation currents below $0.07 \mathrm{~mA} / \mathrm{cm} 2$ and a large and 
stable passive electrochemical window $(-0.5 \mathrm{~V}$ to $+1.0 \mathrm{~V}$ vs. Ag/ $\mathrm{AgCl})$.

- In a biological medium, electrodeposited samples present good corrosion properties compared to standard stainless steels, without incurring pitting.

2. Cytotoxicity tests with the lactate dehydrogenase assay revealed that:

- Electrodeposited Fe-Cr-Ni exhibits low cytotoxicity (cell death

below $0.7 \%$ ), comparable to that of AISI 304 or AISI 316L.

3. Unlike AISI 304 and AISI 316L, which are non-magnetic, electrodeposited Fe-Cr-Ni alloys exhibit soft-magnetic properties:

- Saturation magnetization of electrodeposits linearly decreases

from $662 \mathrm{emu} / \mathrm{cm} 3$ to zero with an increase in $\mathrm{Cr}$ content from $4.8 \mathrm{wt} \%$ to $41.0 \mathrm{wt} \%$.

This unique combination of outstanding corrosion resistance, low cytotoxicity and soft magnetic properties makes the electrodeposited $\mathrm{Fe}-\mathrm{Cr}-\mathrm{Ni}$ alloys of great interest as functional coatings or micro-components for applications in various advanced bio-medical systems.

\section{Acknowledgements}

The authors thank Prof. Dr. Stefano Mischler of EPFL for fruitful discussions and Ms. Zélie Tournoud for her assistance in part of the preparation of electrodeposited samples and polarization experiments. This work was partially supported by the European project SELECTAETN (H2020-MSCA-ITN-2014 no. 642642) and the e-MINDS COST Action (no. MP1407) from the EU Framework Program Horizon 2020. Partial funding from the 2017-SGR-292 project from the Generalitat de Catalunya, and the MAT2017-86357-C3-1-R project (co-financed by the Fondo Europeo de Desarrollo Regional, FEDER) from the Spanish Ministerio de Economía y Competitividad (MINECO) is also acknowledged.

Dr. Eva Pellicer is grateful to MINECO for the "Ramon y Cajal" contract (RYC-2012-10839).

\section{Conflicts of interest}

None.

\section{References}

[1] L.T. Romankiw, A path: from electroplating through lithographic masks in electronics to LIGA in MEMS, Electrochim. Acta 42 (1997) 2985-3005, http://dx.doi. org/10.1016/s0013-4686(97)00146-1.

[2] E.W. Becker, W. Ehrfeld, P. Hagmann, A. Maner, D. Munchmeyer, Fabrication of microstructures with high aspect ratios and great structural heights by synchrotron 
radiation lithography, galvanoforming, and plastic moulding (LIGA process), Microelectron. Eng. 4 (1986) 35-56, http://dx.doi.org/10.1016/0167-9317(86) 90004-3.

[3] J.K. Gansel, M. Thiel, M.S. Rill, M. Decker, K. Bade, V. Saile, G. von Freymann, S. Linden, M. Wegener, Gold helix photonic metamaterial as broadband circular polarizer, Science 325 (2009) 1513-1515, http://dx.doi.org/10.1126/science.

1177031.

[4] D. Routkevitch, T. Bigioni, M. Moskovits, J.M. Xu, Electrochemical fabrication of CdS nanowire arrays in porous anodic aluminum oxide templates, J. Phys. Chem. 100 (1996) 14037-14047, http://dx.doi.org/10.1021/jp952910m.

[5] C. Schönenberger, B.M.I. van der Zande, L.G.J. Fokkink, M. Henny, C. Schmid, M. Krüger, A. Bachtold, R. Huber, H. Birk, U. Staufer, Template synthesis of nanowires in porous polycarbonate membranes: electrochemistry and morphology, J. Phys. Chem. B 101 (1997) 5497-5505, http://dx.doi.org/10.1021/jp963938g. [6] P.V. Braun, P. Wiltzius, Microporous materials - electrochemically grown photonic crystals, Nature 402 (1999) 603-604, http://dx.doi.org/10.1038/45137.

[7] P.V. Braun, P. Wiltzius, Macroporous materials - electrochemically grown photonic crystals, Curr. Opin. Colloid Interface Sci. 7 (2002) 116-123, http://dx.doi.org/10. 1016/s1359-0294(02)00009-2.

[8] Y. Hao, F.Q. Zhu, C.L. Chien, P.C. Searson, Fabrication and magnetic properties of ordered macroporous nickel structures, J. Electrochem. Soc. 154 (2007) D65-D69, http://dx.doi.org/10.1149/1.2400604.

[9] T.S. Eagleton, P.C. Searson, Electrochemical synthesis of 3D ordered ferromagnetic nickel replicas using self-assembled colloidal crystal templates, Chem. Mater. 16 (2004) 5027-5032, http://dx.doi.org/10.1021/cm0491781.

[10] D. Hung, Z. Liu, N. Shah, Y. Hao, P.C. Searson, Finite size effects in ordered macroporous electrodes fabricated by electrodeposition into colloidal crystal templates,

J. Phys. Chem. C 111 (2007) 3308-3313, http://dx.doi.org/10.1021/jp066760z.

[11] S. Zhang, X. Zeng, D.T.A. Matthews, A. Igartua, E. Rodriguez-Vidal, J. Contreras Fortes, V. Saenz De Viteri, F. Pagano, B. Wadman, E.D. Wiklund, E. van der Heide, Selection of micro-fabrication techniques on stainless steel sheet for skin friction, Friction 4 (2016) 89-104, http://dx.doi.org/10.1007/s40544-016-0115-9.

[12] U.M. Attia, J.R. Alcock, A review of micro-powder injection moulding as a microfabrication technique, J. Micromech. Microeng. 21 (2011) 43001, , http://dx.doi. org/10.1088/0960-1317/21/4/043001.

[13] M.R. El-Sharif, A. Watson, C.U. Chisholm, The sustained deposition of thick coatings of chromium/nickel and chromium/nickel/iron alloys and their properties, Trans. IMF 66 (1988) 34-40, http://dx.doi.org/10.1080/00202967.1988.11870801.

[14] J.C. Kang, S.B. Lalvani, C.A. Melendres, Electrodeposition and characterization of amorphous Fe-Ni-Cr-based alloys, J. Appl. Electrochem. 25 (1995) 376-383, http:// dx.doi.org/10.1007/BF00249658.

[15] A. Brenner, Electrodeposition of alloys: PRINCIPLES and, Practice (1963), http:// dx.doi.org/10.1016/B978-1-4831-9807-1.50001-5.

[16] L. Philippe, C. Heiss, J. Michler, Electroplating of stainless steel, Chem. Mater. 20 (2008) 3377-3384, http://dx.doi.org/10.1021/cm703591n.

[17] M. Hasegawa, S. Yoon, G. Guillonneau, Y. Zhang, C. Frantz, C. Niederberger, A. Weidenkaff, J. Michler, L. Philippe, The electrodeposition of FeCrNi stainless steel: microstructural changes induced by anode reactions, Phys. Chem. Chem. Phys. 16 (2014) 26375-26384, http://dx.doi.org/10.1039/c4cp03744h.

[18] C.A. Snavely, A theory for the mechanism of chromium plating - a theory for the 
physical characteristics of chromium plate, J. Electrochem. Soc. 92 (1947)

537-577, http://dx.doi.org/10.1149/1.3071841.

[19] H.H. Uhlig, Passivity in metals and alloys, Corros. Sci. 19 (1979) 777-791, http:// dx.doi.org/10.1016/S0010-938X(79)80104-3.

[20] N. Sato, An overview on the passivity of metals, Corros. Sci. 31 (1990) 1-19, http:// dx.doi.org/10.1016/0010-938X(90)90086-K.

[21] C.O.A. Olsson, D. Landolt, Passive films on stainless steels - chemistry, structure and growth, Electrochim. Acta 48 (2003) 1093-1104, http://dx.doi.org/10.1016/ S0013-4686(02)00841-1.

[22] I. Olefjord, H. Fischmeister, ESCA studies of the composition profile of low temperature oxide formed on chromium steels-II. Corrosion in oxygenated water,

Corros. Sci. 15 (1975) 697-707, http://dx.doi.org/10.1016/0010-938X(75)

90034-7.

[23] C. Calinski, H.H. Strehblow, ISS depth profiles of the passive layer on Fe/Cr alloys, J. Electrochem. Soc. 136 (1989) 1328, http://dx.doi.org/10.1149/1.2096915.

[24] S. Haupt, H.H. Strehblow, A combined surface analytical and electrochemical study of the formation of passive layers on FeCr alloys in 0.5M H2SO4, Corros. Sci. 37

(1995) 43-54, http://dx.doi.org/10.1016/0010-938X(94)00104-E.

[25] M. Kraack, H. Boehni, W. Muster, J. Patscheider, Influence of molybdenum on the corrosion properties of stainless steel films, Surf. Coat. Technol. 68 (1994) 541-545, http://dx.doi.org/10.1016/0257-8972(94)90214-3.

[26] M.W. Tan, E. Akiyama, A. Kawashima, K. Asami, K. Hashimoto, The influence of pre-immersion on the potentiostatic polarization behavior of amorphous Fe-Cr-MoP-C alloys in de-aerated 1M HCl, Corros. Sci. 38 (1996) 1495-1511, http://dx.doi. org/10.1016/0010-938X(96)00040-6.

[27] L. Felloni, S. Sostero Traverso, G.L. Zucchini, G.P. Cammarota, Investigation on the second anodic current maximum on the polarization curves of commercial stainless steels in sulphuric acid, Corros. Sci. 13 (1973) 773-789, http://dx.doi.org/10. 1016/S0010-938X(73)80015-0.

[28] M.S. El-Basiouny, S. Haruyama, The polarization behaviour of $\mathrm{FeCr}$ alloys in acidic sulphate solutions in the active region, Corros. Sci. 16 (1976) 529-540, http://dx. doi.org/10.1016/S0010-938X(76)80030-3.

[29] C.D. Kim, B.E. Wilde, Influence of cathodic pretreatment on theanodic dissolution kinetics of stainless steels in dilute acid media, Corros. Sci. 10 (1970) 735-744, http://dx.doi.org/10.1016/S0010-938X(70)80044-0.

[30] S. Surviliene, O. Nivinskiene, A. Češuniene, A. Selskis, Effect of Cr(III) solution chemistry on electrodeposition of chromium, J. Appl. Electrochem. 36 (2006) 649-654, http://dx.doi.org/10.1007/s10800-005-9105-8.

[31] D.R. Gabe, The role of hydrogen in metal electrodeposition processes, J. Appl. Electrochem. 27 (1997) 908-915, http://dx.doi.org/10.1023/a:1018497401365. [32] J. Porcayo-Calderon, M. Casales-Diaz, V.M. Salinas-Bravo, L. Martinez-Gomez, Corrosion performance of $\mathrm{Fe}-\mathrm{Cr}-\mathrm{Ni}$ alloys in artificial saliva and mouthwash solution, Bioinorg. Chem. Appl. 2015 (2015) 930802, , http://dx.doi.org/10.1155/ 2015/930802.

[33] S. Atalay, H. Gencer, V.S. Kolat, Magnetic entropy change in Fe74 - xCrxCu1Nb3Si13B9 ( $\mathrm{x}=14$ and 17) amorphous alloys, J. Non-Cryst. Solids

351 (2005) 2373-2377, http://dx.doi.org/10.1016/j.jnoncrysol.2005.07.012.

[34] Y. Boliang, J.M.D. Coey, M. Olivier, J.O. Ström-Olsen, Onset of magnetism in ironchromium glasses, J. Appl. Phys. 55 (1984) 1748-1750, http://dx.doi.org/10. 
1063/1.333464.

[35] E. Pellicer, A. Varea, S. Pané, B.J. Nelson, E. Menéndez, M. Estrader, S. Suriñach, M.D. Baró, J. Nogués, J. Sort, Nanocrystalline electroplated Cu-Ni: metallic thin films with enhanced mechanical properties and tunable magnetic behavior, Adv. Funct. Mater. 20 (2010) 983-991, http://dx.doi.org/10.1002/adfm.200901732. 